\title{
Internet addiction and related psychosocial factors among Pakistani population during Covid19
}

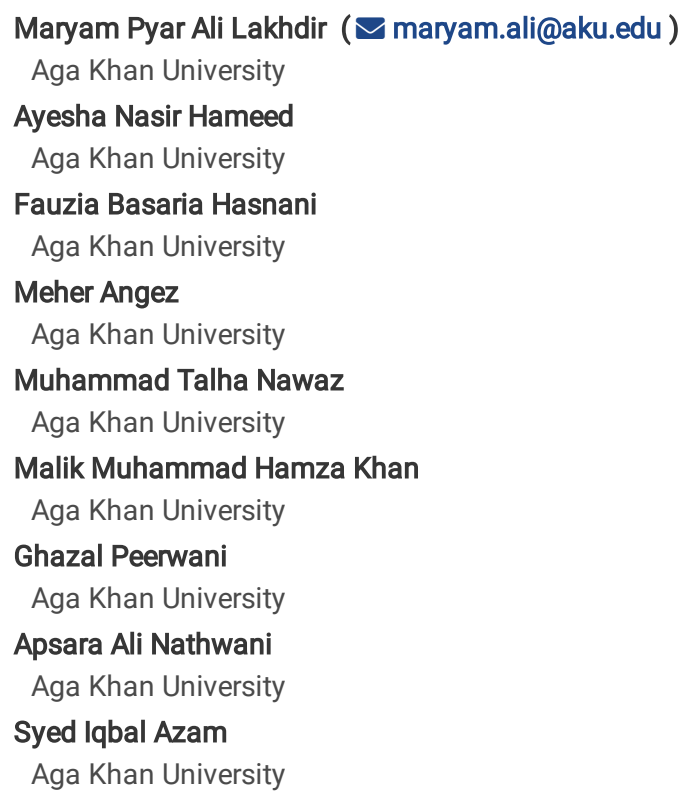

Research Article

Keywords: Internet, Addiction, Survey, Covid-19, Depression, Anxiety, Stress

Posted Date: September 23rd, 2021

DOI: https://doi.org/10.21203/rs.3.rs-927656/v1

License: (c) (1) This work is licensed under a Creative Commons Attribution 4.0 International License. Read Full License 


\section{Abstract Background}

Internet addiction has surfaced as a significant concern to public health in these unprecedented Covid19 times due to social distancing and lockdown. This study aims to determine the burden of internet addiction and related psychosocial factors among the Pakistani population amidst COVID-19

\section{Methods}

An analytical cross-sectional survey was broadcasted on internet via google form link which was completed by 1145 Pakistani residents. The outcome variable was Internet addiction and was assessed using the "Young's Internet Addiction Test" (IAT). In addition, symptoms of depression, anxiety, and stress were evaluated using the "Depression, Anxiety, and Stress Scale-21" (DASS-21). The multinomial logistic regression was applied, and adjusted odds ratio along with 95\% confidence intervals were reported for significant factors associated with Internet addiction.

\section{Results}

The majority of participants were females and youth (between ages 20-24 years). The prevalence of problematic-internet-users (PIU) and addictiveinternet-users (AIU) was $27.3 \%$ and $11.3 \%$, respectively. The odds of extremely severe anxiety among AIU were approximately three times (Adj OR: 2.6 (1.1-7.1) followed by the odds of having extremely severe depression was 3.14 (95\% C.I.: 1.53-6.44) times greater among PIUand odds of extremely severe stress being about five times higher among AIU (Adj OR: 5.42 (1.66-17.68)) as compared to normal-internet-user (NIU).

\section{Conclusion}

Amid Covid 19, the burden of internet addiction was discovered to have surged among the Pakistani populace. This study found that gender, marital status, depression, stress, anxiety, work situation, and mood changes amidst the pandemic are significantly associated with problematic and addictive internet use.

\section{Introduction:}

The internet is having an increasing impact on the lives of both adolescents and adults. While there are numerous benefits, there are also hazards associated with excessive use or addiction. An undue obsession or craving towards computer use and internet access is classified as problematic internet addiction, which has been seen as a growing trend among users amidst Covid19(1). Behavioral addictions like this can take on a variety of hidden and appealing forms. These may appear harmless at first, but they can lead to a vicious circle from which it is difficult to recover, often manifested by an increased compulsion to surf the internet, difficulty in withdrawal, dependability, and uncontrollable desires and may sometimes be associated with other comorbidities such as substance abuse, hyperactivity disorders, anxiousness, sadness, and anger(2).

Internet usage has increased dramatically on a worldwide level over the last decade. According to surveys conducted in the United States and Europe, the burden of internet addiction ranges between 1.5 and 8.2 percent. (1). A large European sample of 11,356 adolescents from 11 countries was investigated, and a prevalence of 4.4 percent was observed. This percentage was higher in males, and the most common reported cause was online gaming. In contrast, the most commonly reported use of the internet among females was for social networking (3). Another survey by Siomos indicated that 8.2 percent of Greek adolescents are addicted to the internet, whereas statistics from German studies show that the burden of internet addiction among adolescents ranges from 1.5 percent to 3.5 percent (4-6). Over the past few years, similar patterns of developing internet addiction have been documented in Asian countries. In China, $17.9 \%$ of high school students and $12.3 \%$ of college students have been found to be addicted to the internet(7, 8). According to research conducted in Taiwan, $18.8 \%$ of people are addicted to the internet, with teens accounting for the majority of those affected(9). Another study found that males with internet addiction were primarily involved in online gaming and poor peer relationships (2). Other reported risk factors for internet addiction included computer accessibility, availability of computer gaming's arena, family dysfunction and conflict, and low parental monitoring(10).

The covid-19 pandemic, in addition to having a devastating effect on the healthcare system, has also unquestionably impacted worldwide social structures and ties. To counteract the effects of social distancing and lockdown, the internet has become more popular and widespread among people of all social strata(11). Consequently, internet addiction and behavioral issues have been skyrocketed in these unprecedented times(12). The use of the internet, specifically websites pertaining to pornography and video gaming, has expanded dramatically during the pandemic. (13, 14). Globally, studies done in many European countries have shown an increase of about $50 \%$ in the rates of internet addiction during the pandemic when compared to before (15). Another study conducted in China via an online survey stated that $46.8 \%$ of the participants had increased internet dependence and the prevalence of dependence on the internet rose by $23 \%$ (from 3.55 to 4.3). Similar trends have been observed in India, where excessive internet usage led to increasing amounts of people playing video games and Binge watching. According to surveys in India, during the pandemic, the number of people playing video games has increased 3 times on the Winzio games platform and $200 \%$ on Paytm first games $(16,17)$. During the pandemic, several reasons have contributed to the rise in internet addiction. The COVID-19 pandemic has imposed an overwhelming economic strain on communities and triggered emotional reactions among the general public(18).To combat covid19, the government imposed measures such as home confinement, constant

Page $2 / 12$ 
lockdown, and the closure of all schools, colleges, universities, offices, businesses, and markets, which resulted in work from home and unemployment, all of which have significantly contributed to the factors that cause internet addiction(19).

The trend of internet addiction in times of the pandemic is also observed a rise in Pakistan. Various press articles and data from the telecom industry indicated a surge in internet usage. The Pakistan Telecommunication Authority claimed a 15\% rise in internet usage, whereas telecom companies reported a $25 \%$ increase in data usage $(20,21)$. However, no evidence-based research has been conducted to observe the rising Internet addiction during the pandemic and the factors associated with it. This increasing trend of internet addiction is an eye-opener amidst the already challenging times of the pandemic. At a period when countries are unprepared to face what Covid-19 has to bring and are already on the verge of economic exhaustion, having to deal with another pandemic in the form of internet addiction would be gruesome. Therefore, it is imperative that this trend is identified for the Pakistani population for which minimal data exists. This study aims to determine the burden of internet addiction among the Pakistani population amidst COVID19 and the psychosocial factors associated with internet addiction, including sociodemographic factors, health-related factors, and behavioral and environmental factors.

\section{Methods:}

A cross-sectional survey was carried out to determine the burden of internet addiction during the pandemic and the effect of various psychological factors, including depression, anxiety, and stress, onto internet addiction. This was a web-based survey circulated on the internet via different social media platforms such as 'WhatsApp' groups, Facebook pages, Twitter, email, etc., using google form link. To ensure adequate survey translation in the local language, the English version was reviewed by the psychiatrist and translated in Urdu and back-translated in English to substantiate comparability of meaning and context. Individuals aged 13 years and above with competency to comprehend English or Urdu language, currently residing in any province of Pakistan, having access to questionnaire, and willing to participate were eligible to participate. Overseas Pakistanis were excluded from the study. Electronic consent was obtained from all the participants, including parental consent for participants underage of 18 years to participate in the study. Assent was further verified by taking the contact information of parents/guardians. Ethical approval was obtained from the institutional ethical review board (Aga Khan University Ethical Review Board).

\section{Dependent variable:}

The outcome of this study was Internet addiction and was assessed by the "Young's Internet Addiction Test (IAT)" to screen symptoms of internet addiction and related disruption in psychosocial functioning. This screening tool is a self-assessment scale with a total of 20 questions, each of which is graded on a 6-point scale from 0 to 5. Participants having an IAT score of 70 and above were categorized as an "addictive-internet-users (AIU)" coded as 2, IAT score of 40 to 69 were categorized as "problematic-internet-users (PIU)" coded as 1, and IAT score of 39 or less were classified as "normal-internetusers (NIU)" coded as 0 . This instrument has shown acceptable psychometric properties and was previously validated in a Pakistani setting showing Cronbach alpha of 0.88 , indicating excellent reliability(22).

\section{Independent Variable:}

Symptoms of depression, anxiety, and stress were screened using the "Depression, Anxiety and Stress Scale-21 (DASS-21)". This scale has been used for the clinical assessment using the symptomatology approach of depression, anxiety, and stress; however, it doesn't indicate the diagnosis of cases. This tool measures severity/frequency of symptoms and is a 4-point scale from 0 to 3 where: $0=$ "it does not apply to me at all," $1=$ "it applies to me to some degree or some of the time," $2=$ "it applies to me to a considerable degree or a good part of the time," and $3=$ "it applies to me very much, or most of the time." To compute the final score for each psychological condition(depression, anxiety, and stress), scores for items related to each condition were summed and further multiplied by 2 . Scores for all psychological conditions ranged from $0-42$. Each participant's responses were grouped into one of the five categories: normal, mild, moderate, severe, and extremely severe for depression, anxiety and stress separately. For depression, participants with a score of 0 to 9 were categorized as 'normal, a score of 10 to 13 as 'mild,' a score of 14 to 20 as 'moderate,' a score of 21 to 27 as 'severe,' and a score of 28 or higher as 'extremely severe.'For anxiety, participants with a score of 0 to 7 were categorized as 'normal,' a score of 8 to 9 as 'mild,' a score of 10 to 14 as 'moderate,' a score of 15 to19 as 'severe,' and a score of 20 or higher as 'extremely severe.' For stress, participants with a score of 0 to 14 were categorized as 'normal, a score of 15 to 18 as 'mild,' a score of 19 to 25 as 'moderate,' a score of 26 to 33 as 'severe,' and a score of 34 or higher as 'extremely severe.' This instrument has shown excellent psychometric properties and has been previously used in Pakistani settings showing internal consistency (Cronbach's a) of 0.84 to $0.97(23)$.

Other variables, including sociodemographic, health-related, and behavioral and environmental factors related to the pandemic, were also collected.

\section{Sample Size}

The estimated sample size came to be a minimum of 1,145 for determining the burden and related psychological factors of internet addiction. For the burden of internet addiction (PIU and AIU) among the Pakistani population, the burden was expected in the range from 9.7-47\% with $2.5 \%$ of absolute precision and a level of significance of $5 \%$; found a minimum sample of 379 individuals was required. For assessing the effect of depression, anxiety, and stress on internet addiction, a minimum sample of 994 individuals was required to achieve $80 \%$ power and at $95 \%$ level of significance, with the range of non-diseased (normal internet user) with depression, anxiety and stress ranging from $28-33 \%$ and an anticipated odd ratio of 1.5 . As it was a web-based study, $15 \%$ of refusals and incomplete forms were anticipated. The final sample size came to be 1145 , including $15 \%$ of refusals and incomplete forms. A non-probability purposive sampling technique was adopted. 
Statistical analysis was done using Stata version 16. Mean and standard deviation were computed for all continuous variablesand frequencies, and percentages were computed for all categorical variables. All descriptive statistics were reported based on internet addiction. Overall mean and standard deviation were reported for depression, anxiety and stress and were stratified based on internet addiction and gender. Multinominal logistic regression was used to assess the effect of psychological conditions (Depression, Anxiety, and stress) and other factors on the internet addiction amidst Covid19. Adjusted odds ratio along with the confidence interval of $95 \%$ were reported. A p-value of less than $5 \%$ was considered significant.

\section{Results:}

Among 1145 participants, 703 (61.4\%) had IAT score 39 or below and hence were found to be normal internet users, 313 (27.3\%) were problematic internet users (IAT score 40-69), and 129 (11.3\%) were addictive internet users having IAT score 70 or above. The majority of the participants were females (about 60\%) in each of the three groups of internet users, and the majority were youth, i.e., having age 20 to 24 years in each group. Among normal internet users, $79.8 \%$ were single, i.e., never married, whereas, among problematic and addictive users, proportions of never-married participants were $87.5 \%$ and $84.5 \%$, respectively ( $p$-value $<0.01$ ). Most of the participants belonged to the nuclear family system, and this distribution was not found to be significantly different in the three groups ( $p$-value $=0.65$ ). About $21 \%$ of the normal users, about $16 \%$ of the problematic users, and $18.6 \%$ of the addictive users had a post-graduate degree $(p$-value $=0.03$ ). Moreover, $13.2 \%$ of the addictive users had a family income of rupees less than 50 thousand compared to $23.3 \%$ of problematic users and $33.7 \%$ of normal users ( $p$-value $<0.001$ ). (Table $1 a)$

DASS-21 results showed that $47.3 \%$ of the addictive internet users were found to be extremely severely depressed as compared to only $6.8 \%$ of the normal internet users. Similarly, $55.8 \%$ of the addictive internet users versus $11.4 \%$ of the normal internet users were having extremely severe anxiety, and $25.6 \%$ of the addictive vs. $2.3 \%$ of the normal internet users were extremely severely depressed. All these differences were found to be highly significant (p-value < 0.01) (Table 1b)

About $41 \%$ of the addictive internet users (vs. $37 \%$ of the normal internet users) had a history of mental health problems. Moreover, $27.9 \%$ of the addictive users versus $20.7 \%$ of the normal users reported that their family members suffered from mental issues during COVID. (Table $1 \mathrm{c}$ )

The work situation of the participants was also found to be significantly different ( $p$-value $<0.01)$ among the three groups of internet users, showing $53.5 \%$ of the addictive users were not working as compared to $45.7 \%$ of the normal users who were not working. However, workload and financial impact on budget due to the pandemic was not found to be significantly different in the three groups (Table 1d)

The mood of participants during the pandemic was significantly different (p-value $<0.001)$ in the three groups of internet users with $74.4 \%$ of addictive users having negative moods compared to $45.7 \%$ of the normal users. (Table $1 \mathrm{~d}$ ) 
Table 1

showing sociodemographic factors, health related factors and behavioral and environmental factors of participants $(n=1145)$

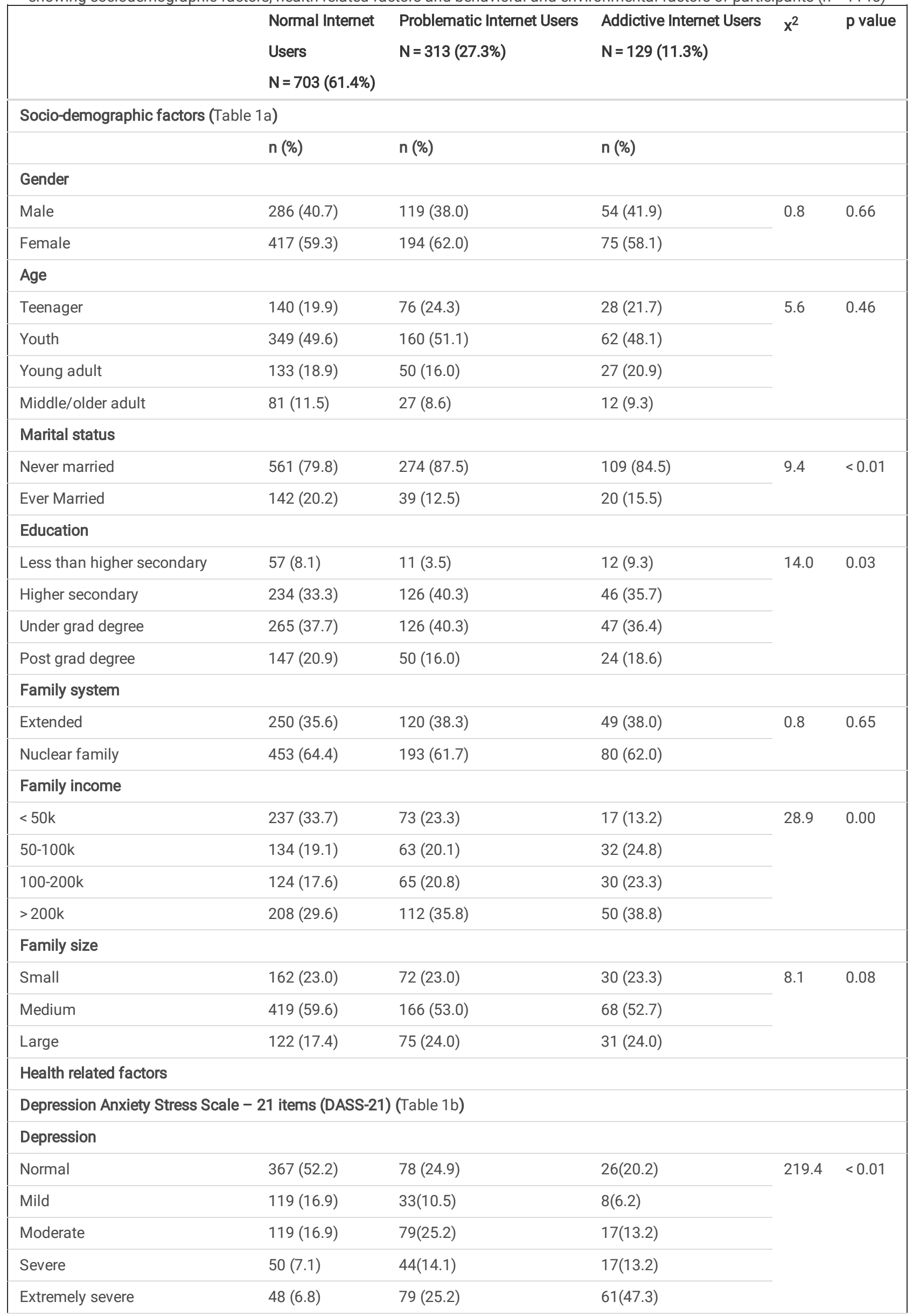




\begin{tabular}{|c|c|c|c|c|c|}
\hline & $\begin{array}{l}\text { Normal Internet } \\
\text { Users } \\
\mathrm{N}=703(61.4 \%)\end{array}$ & $\begin{array}{l}\text { Problematic Internet Users } \\
\mathrm{N}=313(27.3 \%)\end{array}$ & $\begin{array}{l}\text { Addictive Internet Users } \\
\mathrm{N}=129 \text { (11.3\%) }\end{array}$ & $x^{2}$ & $p$ value \\
\hline \multicolumn{6}{|l|}{ Anxiety } \\
\hline Normal & $350(49.8)$ & $80(25.6)$ & $24(18.6)$ & \multirow[t]{5}{*}{199.6} & \multirow[t]{5}{*}{$<0.01$} \\
\hline Mild & $83(11.8)$ & $22(7.0)$ & $4(3.1)$ & & \\
\hline Moderate & $156(22.2)$ & $67(21.4)$ & $19(14.7)$ & & \\
\hline Severe & $34(4.8)$ & $39(12.5)$ & $10(7.8)$ & & \\
\hline Extremely severe & $80(11.4)$ & $105(33.6)$ & $72(55.8)$ & & \\
\hline \multicolumn{6}{|l|}{ Stress } \\
\hline Normal & $532(75.7)$ & $144(46.0)$ & $39(30.2)$ & \multirow[t]{5}{*}{234.3} & \multirow[t]{5}{*}{$<0.01$} \\
\hline Mild & $51(7.3)$ & $35(11.2)$ & $4(3.1)$ & & \\
\hline Moderate & $63(9.0)$ & $54(17.3)$ & 14(10.9) & & \\
\hline Severe & $41(5.8)$ & $53(16.9)$ & $39(30.2)$ & & \\
\hline Extremely severe & $16(2.3)$ & $27(8.6)$ & $33(25.6)$ & & \\
\hline \multicolumn{6}{|c|}{ History of any mental health problems (Table 1c) } \\
\hline No & $366(52.1)$ & $119(38.0)$ & $58(45.0)$ & \multirow[t]{3}{*}{17.9} & \multirow[t]{3}{*}{$<0.01$} \\
\hline Yes & $260(37.0)$ & $146(46.7)$ & $53(41.1)$ & & \\
\hline I don't know & $77(11.0)$ & $48(15.3)$ & $18(14.0)$ & & \\
\hline \multicolumn{6}{|c|}{ Family members suffering from mental problem during Covid (Table 1c) } \\
\hline No & $485(69.0)$ & $173(55.3)$ & $74(57.4)$ & \multirow[t]{3}{*}{23.4} & \multirow[t]{3}{*}{$<0.01$} \\
\hline Yes & $146(20.8)$ & $82(26.2)$ & $36(27.9)$ & & \\
\hline I don't know & $72(10.2)$ & $58(18.5)$ & $19(14.7)$ & & \\
\hline \multicolumn{6}{|c|}{ Behavioral and environmental factors during pandemic (Table 1d) } \\
\hline \multicolumn{6}{|l|}{ Work situation during pandemic } \\
\hline No, I do not work & $321(45.7)$ & $172(55.0)$ & $69(53.5)$ & \multirow[t]{5}{*}{21.8} & \multirow[t]{5}{*}{$<0.01$} \\
\hline No, looking for job & $62(8.8)$ & $19(6.1)$ & $5(3.9)$ & & \\
\hline No, short time work & $55(7.8)$ & $29(9.3)$ & $16(12.4)$ & & \\
\hline Yes, on work site and teleworking & $98(13.9)$ & $46(14.7)$ & $12(9.3)$ & & \\
\hline Yes, on worksite exclusively & $167(23.8)$ & $47(15.0)$ & $27(20.9)$ & & \\
\hline \multicolumn{6}{|l|}{ Workload during pandemic } \\
\hline Not working & $221(31.4)$ & $121(38.7)$ & $48(37.2)$ & \multirow[t]{5}{*}{11.3} & \multirow[t]{5}{*}{0.18} \\
\hline Higher than before & $137(19.5)$ & $62(19.8)$ & $27(20.9)$ & & \\
\hline Highly variable & $66(9.4)$ & $31(9.9)$ & $15(11.6)$ & & \\
\hline Less than before & $164(23.3)$ & $51(16.3)$ & $23(17.8)$ & & \\
\hline Same as before & $115(16.4)$ & $48(15.3)$ & $16(12.4)$ & & \\
\hline \multicolumn{6}{|c|}{ Financial impact on budget due to pandemic } \\
\hline No & $214(30.4)$ & $82(26.2)$ & $33(25.6)$ & \multirow[t]{3}{*}{7.0} & \multirow[t]{3}{*}{0.13} \\
\hline Yes a little & $336(47.8)$ & $146(46.7)$ & $57(44.2)$ & & \\
\hline Yes a lot & $153(21.8)$ & $85(27.2)$ & $39(30.2)$ & & \\
\hline \multicolumn{6}{|c|}{ Describe your mood during pandemic } \\
\hline Negative & $321(45.7)$ & $178(56.9)$ & $96(74.4)$ & 43.6 & $<0.01$ \\
\hline
\end{tabular}




\begin{tabular}{|c|c|c|c|c|c|}
\hline & $\begin{array}{l}\text { Normal Internet } \\
\text { Users } \\
\mathrm{N}=703(61.4 \%)\end{array}$ & $\begin{array}{l}\text { Problematic Internet Users } \\
\mathrm{N}=313(27.3 \%)\end{array}$ & $\begin{array}{l}\text { Addictive Internet Users } \\
N=129(11.3 \%)\end{array}$ & $x^{2}$ & $p$ value \\
\hline No change & $224(31.9)$ & $70(22.4)$ & $14(10.9)$ & & \\
\hline Positive & $158(22.5)$ & 65 (20.8) & 19 (14.7) & & \\
\hline
\end{tabular}

Overall, the mean depression score of participants among addictive users was $23.4 \pm 12.9$ compared to $18.2 \pm 11.4$ and $10.5 \pm 9.5$ in the problematic and normal internet users, respectively. Similarly, the overall mean anxiety score was much higher in the addictive internet users than problematic and normal users (20.2 vs. 15.1 and 8.6 ). Overall mean stress score was also found to be significantly higher in addictive internet users as compared to problematic and normal internet users ( $p$-value < 0.01) (Table 2). Moreover, we found that mean scores for depression, anxiety, and stress were significantly higher in females as compared to males (Table 2, Fig. 1)

Table 2

showing DASS -21 scores of participants as a function of gender. ( $M=$ male; $F=$ female; $S D=$ standard deviation)

\begin{tabular}{|c|c|c|c|c|c|c|c|c|c|c|c|c|c|c|c|}
\hline & \multicolumn{3}{|c|}{$\begin{array}{l}\text { Normal Intemet Users } \\
\text { Mean (SD) }\end{array}$} & \multicolumn{3}{|c|}{$\begin{array}{l}\text { Problematic Internet } \\
\text { Users Mean (SD) }\end{array}$} & \multicolumn{3}{|c|}{$\begin{array}{l}\text { Addictive Internet Users } \\
\text { Mean (SD) }\end{array}$} & \multicolumn{3}{|c|}{ F factor } & \multicolumn{3}{|c|}{$P$ value } \\
\hline & M & $\mathbf{F}$ & Overall & M & $\mathbf{F}$ & Overall & M & $\mathbf{F}$ & Overall & M & $\mathbf{F}$ & Overall & M & $\mathbf{F}$ & Overal \\
\hline \multicolumn{16}{|c|}{ Depression Anxiety Stress Scale - 21 (DASS-21) scores } \\
\hline $\begin{array}{l}\text { Depression } \\
\text { score }\end{array}$ & $\begin{array}{l}9.1 \\
(8.2)\end{array}$ & $\begin{array}{l}11.4 \\
(10.1)\end{array}$ & $\begin{array}{l}10.5 \\
(9.5)\end{array}$ & $\begin{array}{l}17.3 \\
(10.8)\end{array}$ & $\begin{array}{l}18.8 \\
(11.8)\end{array}$ & $\begin{array}{l}18.2 \\
(11.4)\end{array}$ & $\begin{array}{l}21.0 \\
(13.3)\end{array}$ & $\begin{array}{l}25.2 \\
(12.4)\end{array}$ & $\begin{array}{l}23.4 \\
(12.9)\end{array}$ & 53.1 & 67.1 & 117.4 & 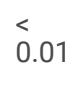 & $<0$ & $<0.01$ \\
\hline $\begin{array}{l}\text { Anxiety } \\
\text { score }\end{array}$ & $\begin{array}{l}7.8 \\
(7.1)\end{array}$ & $\begin{array}{l}9.2 \\
(8.5)\end{array}$ & $\begin{array}{l}8.6 \\
(8.0)\end{array}$ & $\begin{array}{l}14.3 \\
(9.2)\end{array}$ & $\begin{array}{l}15.6 \\
(10.5)\end{array}$ & $\begin{array}{l}15.1 \\
(10.0)\end{array}$ & $\begin{array}{l}17.9 \\
(12.2)\end{array}$ & $\begin{array}{l}22.0 \\
(11.9)\end{array}$ & $\begin{array}{l}20.2 \\
(12.1)\end{array}$ & 48.0 & 72.2 & 118.6 & 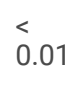 & 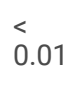 & $<0.01$ \\
\hline $\begin{array}{l}\text { Stress } \\
\text { Score }\end{array}$ & $\begin{array}{l}9.5 \\
(7.9)\end{array}$ & $\begin{array}{l}11.6 \\
(9.4)\end{array}$ & $\begin{array}{l}10.8 \\
(8.9)\end{array}$ & $\begin{array}{l}17.0 \\
(10.0)\end{array}$ & $\begin{array}{l}18.3 \\
(10.6)\end{array}$ & $\begin{array}{l}17.8 \\
(10.4)\end{array}$ & $\begin{array}{l}20.6 \\
(12.8)\end{array}$ & $\begin{array}{l}25.5 \\
(11.8)\end{array}$ & $\begin{array}{l}23.5 \\
(12.4)\end{array}$ & 50.2 & 75.7 & 123.2 & $\dot{0} 01$ & $\dot{0} 0.01$ & $<0.01$ \\
\hline
\end{tabular}

Our final multinomial logistic regression model showed that gender was significantly associated with internet use. The odds of being male were higher (Adj OR: 1.7 (1.1-2.7))in addictive users compared to normal users when controlled for other variables. Similarly, being single was found to have higher odds with problematic internet use (Adjusted OR: 1.6 (1.1-2.5)). Moreover, the odds of having extremely severe depression were3.1 (95\% C.I.: 1.5-6.4) times greater in problematic users than normal internet users. Anxiety was also significantly associated with internet use, odds of extremely severe anxiety being about 3 times higher in addictive users (Adj OR: 2.6 (1.1-7.1)as compared to normal users. Stress was also significantly associated with internet use, odds of extremely severe stress being about five times higher in addictive users (Adj OR: 5.4 (1.7-17.7)). Furthermore, participants who do not work had greater odds of being addictive users (Adj OR: $2.2(1.1-4.6)$ ). Mood changes during the pandemic were also significantly associated with internet use, with odds of negative mood change being greater (Adj OR: 2.9 (1.5-5.6)) in addictive internet users as compared to normal internet users (Table 3) 
Table 3

showing crude and adjusted odds ratio (OR) along with 95\% confidence interval $(\mathrm{Cl})$ of factors associated with internet addiction using multinominal logistic regression. * indicates results with $P$ value $<0.05$.

\begin{tabular}{|c|c|c|}
\hline \multirow[t]{2}{*}{ Variable } & Problematic intemet User (PIU) & Addictive Internet User (AIU) \\
\hline & Adjusted OR (95\% Cl) & Adjusted OR (95\% Cl) \\
\hline \multicolumn{3}{|c|}{ Sociodemographic factors } \\
\hline \multicolumn{3}{|l|}{ Gender } \\
\hline Male & $1.2(0.8-1.6)$ & $1.7(1.1-2.7)$ * \\
\hline \multicolumn{3}{|l|}{ Marital status } \\
\hline Never married & $1.6(1.0-2.5)$ * & $1.5(0.8-2.8)$ \\
\hline \multicolumn{3}{|l|}{ Family income } \\
\hline $50-100 k$ & $1.3(0.9-2.1)$ & $2.8(1.4-5.7)$ * \\
\hline 100-200k & $1.3(0.9-2.1)$ & $2.6(1.3-5.2)$ * \\
\hline$>200 k$ & $1.3(0.9-2.0)$ & $2.3(1.2-4.4)$ * \\
\hline \multicolumn{3}{|l|}{ Family size } \\
\hline Small & $1.2(0.8-1.7)$ & $1.1(0.7-2.0)$ \\
\hline Large & $1.8(1.3-2.7)$ * & $1.8(1.1-3.2)$ * \\
\hline \multicolumn{3}{|c|}{ Health related factors } \\
\hline \multicolumn{3}{|c|}{ Depression Anxiety Stress Scale - 21 (DASS-21) } \\
\hline \multicolumn{3}{|l|}{ Depression } \\
\hline Mild & $1.1(0.7-1.8)$ & $0.8(0.3-1.8)$ \\
\hline Moderate & $2.0(1.3-3.2) *$ & $1.1(0.4-2.3)$ \\
\hline Severe & $2.1(1.1-3.9)$ * & $1.1(0.4-3.3)$ \\
\hline Extremely severe & $3.1(1.5-6.4)$ * & $1.9(0.7-5.7)$ \\
\hline \multicolumn{3}{|l|}{ Stress } \\
\hline Mild & $1.2(0.7-2.0)$ & $0.5(0.2-1.7)$ \\
\hline Moderate & $1.1(0.6-1.9)$ & $1.2(0.5-3.0)$ \\
\hline Severe & $1.2(0.6-2.5)$ & $3.3(1.2-8.9)$ * \\
\hline Extremely severe & $1.2(0.5-3.2)$ & $5.4(1.7-17.7)$ * \\
\hline \multicolumn{3}{|l|}{ Anxiety } \\
\hline Mild & $1.1(0.6-1.7)$ & $0.7(0.2-2.2)$ \\
\hline Moderate & $1.2(0.8-1.9)$ & $1.4(0.7-3.1)$ \\
\hline Severe & $2.6(1.4-4.9)$ * & $2.1(0.7-6.3)$ \\
\hline Extremely severe & $2.0(1.1-3.9)$ * & $2.6(1.1-7.1)$ \\
\hline \multicolumn{3}{|c|}{ Family members suffering from mental problem during Covid } \\
\hline Yes & $1.4(1.0-2.0)$ & $1.1(0.7-1.9)$ \\
\hline I don't know & $1.7(1.1-2.6)$ * & $1.3(0.7-2.5)$ \\
\hline \multicolumn{3}{|c|}{ Behavioral and environmental factors during pandemic } \\
\hline \multicolumn{3}{|c|}{ Work situation during pandemic } \\
\hline Do not work & $1.3(0.8-2.0)$ & $2.2(1.0-4.6)$ * \\
\hline Looking for job & $0.7(0.3-1.3)$ & $0.7(0.2-2.2)$ \\
\hline Part-time job & $1.2(0.7-2.3)$ & $2.6(1.0-6.5)$ * \\
\hline Work in person & $0.7(0.4-1.1)$ & $1.5(0.7-3.4)$ \\
\hline
\end{tabular}

Page 8/12 


\begin{tabular}{|c|c|c|}
\hline \multirow[t]{2}{*}{ Variable } & Problematic intemet User (PIU) & Addictive Internet User (AIU) \\
\hline & Adjusted OR (95\% Cl) & Adjusted OR (95\% Cl) \\
\hline \multicolumn{3}{|c|}{ Describe your mood changes during pandemic } \\
\hline Negative & $1.2(0.8-1.7)$ & $2.9(1.5-5.6)$ * \\
\hline Positive & $1.1(0.7-1.8)$ & $1.5(0.7-3.3)$ \\
\hline
\end{tabular}

\section{Discussion:}

This study indicates that the majority are normal internet users (61.4\%), whereas the prevalence of problematic and addictive internet use is $27.3 \%$ and $11.3 \%$, respectively. The factors that are found to be significantly associated with internet use are gender, marital status, depression, stress, work situation, and mood changes during the COVID-19 pandemic.

While the majority were normal internet users in our study, the proportions of problematic and addictive internet use are not considerably less. Moreover, the literature reveals that measures to curb the COVID-19 pandemic such as lockdowns, closure of educational institutions, closure of entertainment clubs, and promotion of work from home practices have led to an increase in time spent at home and have contributed remarkably in increased and possibly addictive use of the internet(13,14, 19).

In this study, males are found to be more addictive users. This finding is consistent with many previous studies(24, 25)with the possible reason that males are more involved in online gaming and are more prone to use the internet for entertainment and leisure activities in comparison to females. However, some studies show females are more addicted to internet use attributing it to online shopping addiction, especially in the recent few years with the advent of more online shopping websites $(26,27)$.

This study further revealed that single participants have greater odds of being addictive internet users. This finding is compatible with few studies (28). The possible explanation could be that married life poses certain responsibilities and demands more time towards family, limiting many leisure activities like internet use. On the other hand, unmarried individuals may spend more time on the internet to compensate for family life and social interaction, especially during the lockdown in pandemics where internet use can serve to communicate and develop a virtual friendship. However, we also found studies where marital status had no association with internet use(29).

Our results show that severe depression, severe stress, and negative mood changes during a pandemic are significantly associated with addictive internet use. These findings are in line with the literature $(30,31)$. Behaviors like internet addiction may serve as a coping strategy to reduce stress and depression and to avoid negative thoughts $(32,33)$. Another finding of this study is that not working situation is significantly associated with addictive use of the internet. Literature shows that unemployment during the COVID-19 pandemic has markedly contributed to the factors responsible for internet addiction(19).

Our study was unique in our settings, with quite a large sample size and considering several variables. However, it has some limitations. Firstly, it was a web-based survey, so the sample may not be representative, and findings may not be generalized to the entire population. Also, information bias and selection bias cannot be eliminated in a web-based study. Moreover, due to the cross-sectional design of the study, the temporal relationship cannot be studied. However, future such research in this area can make use of prospective, longitudinal designs to establish temporal associations.

\section{Conclusion}

While the Internet is increasingly becoming an integral part of our lives in the modern era, its excessive use has potentially addictive effects that lead to serious mental health problems. Moreover, with the COVID-19 pandemic, increased use of the internet possibly leading to addictive behaviors that need to be carefully monitored. This study, unique of its kind in Pakistan, identified that gender, marital status, depression, stress, anxiety, work situation, and mood changes during the COVID-19 pandemic are significantly correlated with problematic and addictive internet use. These findings could serve as a preliminary step towards early awareness and preventing measures against the addictive use of the internet to avoid or mitigate any serious mental health problems that we may run into, especially during these crucial times of the COVID-19 pandemic.

\section{Declarations}

Ethics approval and consent to participate: Ethical approval was taken from The Aga Khan University Ethical Review Committee (2020-5750-14980). All procedures performed in studies involving human participants were in accordance with the ethical standards of the institutional committee.

Informed consent: Before data collection (access to electronic form), all participants were asked to electronically sign a form of consent to be included in this study.

Consent for publication: The authors consent for publication of this paper. All authors have read and approved the final manuscript. This manuscript has not been published and is not under consideration for publication elsewhere. 
Availability of data and materials: The data that support the findings of this study are available on request from the corresponding author. The data are not publicly available due to information that could compromise the privacy of research participants.

Competing interests: The authors declare that they have no competing interests. The authors report no conflict of interest.

Authors' contributions: Conception or design of the work: MPL; Proposal development: MPL, ANH, MA, MTN, MMHK; Proposal review: GP, AA, SIA; Data collection: MPL, ANH, MA, MTN, MMHK, GP; Data Cleaning: MPL, ANH, MA, MTN, MMHK, AA and Data Coding: MPL, ANH, MA, MTN, MMHK, SIA; Data

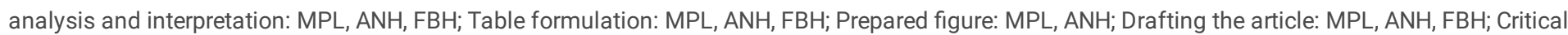
revision of the article: MPL, GP, SIA; Final approval of the version to be published: MPL, ANH, MA, MTN, MMHK, FBH, GP, AA, SIA. All authors read and approved the final manuscript.

Acknowledgements: Special thanks to Wahab Fazal, Fatima Zehra and Naila Qurban for their participation in the broadcasting of the google link during data collection process.

\section{Corresponding Author Detail:}

Maryam Pyar Ali Lakhdir

Senior Instructor,

Aga Khan University Department of Community Health Sciences,

First Floor, Stadium Road, P.O Box 3500

Karachi, Pakistan. Office No: 00922134864813

Email Address: maryam.ali@aku.edu

maryampyarali.lakhdir@gmail.com

\section{References}

1. Weinstein A, Lejoyeux M. Internet Addiction or Excessive Internet Use. Am J Drug Alcohol Abuse. 2010 Aug;36(5):277-83.

2. Jorgenson AG, Hsiao RC-J, Yen C-F. Internet Addiction and Other Behavioral Addictions. Child Adolesc Psychiatr Clin N Am. 2016 Jul;25(3):509-20.

3. Durkee T, Kaess M, Carli V, Parzer P, Wasserman C, Floderus B, et al. Prevalence of pathological internet use among adolescents in Europe: demographic and social factors. Addiction [Internet]. 2012 Dec 1 [cited 2021 Apr 9];107(12):2210-22. Available from:

http://doi.wiley.com/10.1111/j.1360-0443.2012.03946.x

4. Peukert P, Sieslack S, Barth G, Batra A. Internet- und computerspielabhängigkeit: Phänomenologie, komorbidität, ätiologie, diagnostik und therapeutische implikationen für betroffene und angehörige [Internet]. Vol. 37, Psychiatrische Praxis. @ G Georg Thieme Verlag KG Stuttgart · New York; 2010 [cited 2021 Apr 9]. p. 219-24. Available from: http://www.thieme-connect.de/DOI/DOI?10.1055/s-0030-1248442

5. BAKKEN IJ, WENZEL HG, GÖTESTAM KG, JOHANSSON A, ØREN A. Internet addiction among Norwegian adults: A stratified probability sample study. Scand J Psychol [Internet]. 2009 Apr 1 [cited 2021 Apr 9];50(2):121-7. Available from: http://doi.wiley.com/10.1111/j.1467-9450.2008.00685.x

6. Siomos KE, Dafouli ED, Braimiotis DA, Mouzas OD, Angelopoulos N V. Internet addiction among greek adolescent students. Cyberpsychology Behav [Internet]. 2008 Dec 1 [cited 2021 Apr 9];11(6):653-7. Available from: https://www.liebertpub.com/doi/abs/10.1089/cpb.2008.0088

7. Yen JY, Ko CH, Yen CF, Wu HY, Yang MJ. The Comorbid Psychiatric Symptoms of Internet Addiction: Attention Deficit and Hyperactivity Disorder (ADHD), Depression, Social Phobia, and Hostility. J Adolesc Heal. 2007 Jul 1;41(1):93-8.

8. Yen JY, Yen CF, Chen CS, Tang TC, Ko CH. The association between adult ADHD symptoms and internet addiction among college students: The gender difference. Cyberpsychology Behav [Internet]. 2009 Apr 1 [cited 2021 Apr 9];12(2):187-91. Available from:

https://www.liebertpub.com/doi/abs/10.1089/cpb.2008.0113

9. Ko CH, Yen JY, Liu SC, Huang CF, Yen CF. The Associations Between Aggressive Behaviors and Internet Addiction and Online Activities in Adolescents. J Adolesc Heal. 2009 Jun 1;44(6):598-605.

10. Park SK, Kim JY, Cho CB. Prevalence of Internet addiction and correlations with family factors among South Korean adolescents. Adolescence. 2008;43(172):895-909.

11. Deslandes SF, Coutinho T. O uso intensivo da internet por crianças e adolescentes no contexto da COVID-19 e os riscos para violências autoinflingidas. Vol. 25, Ciência \& Saúde Coletiva. scielo ; 2020. p. 2479-86.

12. Dubey MJ, Ghosh R, Chatterjee S, Biswas P, Chatterjee S, Dubey S. COVID-19 and addiction. Diabetes Metab Syndr. 2020/06/09. 2020;14(5):817-23.

13. Király O, Potenza MN, Stein DJ, King DL, Hodgins DC, Saunders JB, et al. Preventing problematic internet use during the COVID-19 pandemic: Consensus guidance. Compr Psychiatry. 2020/05/12. 2020 Jul;100:152180.

Page 10/12 
14. King DL, Delfabbro PH, Billieux J, Potenza MN. Problematic online gaming and the COVID-19 pandemic. J Behav Addict. 2020 Jun;9(2):184-6.

15. Rolland B, Haesebaert F, Zante E, Benyamina A, Haesebaert J, Franck N. Global Changes and Factors of Increase in Caloric/Salty Food Intake, Screen Use, and Substance Use During the Early COVID-19 Containment Phase in the General Population in France: Survey Study. JMIR Public Heal Surveill. 2020;6(3):e19630.

16. Amin KP, Griffiths MD, Dsouza DD. Online Gaming During the COVID-19 Pandemic in India: Strategies for Work-Life Balance. Int J Ment Health Addict. 2020;1-7.

17. Dixit A, Marthoenis M, Arafat SMY, Sharma P, Kar SK. Binge watching behavior during COVID 19 pandemic: A cross-sectional, cross-national online survey. Psychiatry Res. 2020;

18. Dubey S, Biswas P, Ghosh R, Chatterjee S, Dubey MJ, Chatterjee S, et al. Psychosocial impact of COVID-19. Diabetes Metab Syndr. 2020/05/27. 2020;14(5):779-88.

19. Czeisler MÉ, Lane RI, Petrosky E, Wiley JF, Christensen A, Njai R, et al. Mental health, substance use, and suicidal ideation during the COVID-19 pandemic-United States, June 24-30, 2020. Morb Mortal Wkly Rep. 2020;69(32):1049.

20. DATA USAGE - Profit by Pakistan Today [Internet]. [cited 2021 Apr 9]. Available from: https://profit.pakistantoday.com.pk/2020/09/10/data-usagejumped-25pc-revenue-from-voice-traffic-declined-10pc-during-lockdown/data-usage/

21. Pakistan's internet use surges amid COVID-19 lockdown [Internet]. [cited 2021 Apr 9]. Available from: https://www.aa.com.tr/en/asiapacific/pakistan-s-internet-use-surges-amid-covid-19-lockdown/1807118

22. Ndasauka Y, Pitafi A, Kayange GM. Psychometric properties of Young's Internet Addiction Test (IAT) in Urdu language. Asian J Psychiatr. 2019 Feb 1;40:39-44.

23. JPMA - Journal Of Pakistan Medical Association [Internet]. [cited 2021 Sep 21]. Available from: https://jpma.org.pk/article-details/9195

24. Sharma A, Sahu R, Kasar PK, Sharma R. Internet addiction among professional courses students: A study from central India. Int J Med Sci Public Heal. 2014;3(9):1069-73.

25. Chaudhari B, Menon P, Saldanha D, Tewari A, Bhattacharya L. Internet addiction and its determinants among medical students. Ind Psychiatry J. 2015;24(2):158.

26. Ahmer Z, Tanzil S. Internet addiction among social networking sites users: Emerging mental health concern among medical undergraduates of Karachi. Pakistan J Med Sci. 2018;34(6):1473.

27. Tang CS, Koh YYW. Online social networking addiction among college students in Singapore: Comorbidity with behavioral addiction and affective disorder. Asian J Psychiatr. 2017;25:175-8.

28. Iravani M, Rajabi M, Abbasi M, Jannesari H. A social work study on impact of gender, marital status and employment status on internet addiction. Manag Sci Lett. 2013;3(3):1019-24.

29. Dib JE, Haddad C, Sacre H, Akel M, Salameh P, Obeid S, et al. Factors associated with problematic internet use among a large sample of Lebanese adolescents. BMC Pediatr. 2021;21(1):1-12.

30. Obeid S, Saade S, Haddad C, Sacre H, Khansa W, Al Hajj R, et al. Internet addiction among Lebanese adolescents: the role of self-esteem, anger, depression, anxiety, social anxiety and fear, impulsivity, and aggression-a cross-sectional study. J Nerv Ment Dis. 2019;207(10):838-46.

31. Matar Boumosleh J, Jaalouk D. Depression, anxiety, and smartphone addiction in university students-A cross sectional study. PLoS One. 2017;12(8):e0182239.

32. Király O, Urbán R, Griffiths MD, Ágoston C, Nagygyörgy K, Kökönyei G, et al. The mediating effect of gaming motivation between psychiatric symptoms and problematic online gaming: An online survey. J Med Internet Res. 2015;17(4):e88.

33. Blasi M Di, Giardina A, Giordano C, Coco G Lo, Tosto C, Billieux J, et al. Problematic video game use as an emotional coping strategy: Evidence from a sample of MMORPG gamers. J Behav Addict. 2019;8(1):25-34.

34. <background-color:\#CCCCFF;bu>Internet addiction and factors associated with internet addiction during COVID-19</background-color:\#CCCCFF;bu>

\section{Figures}




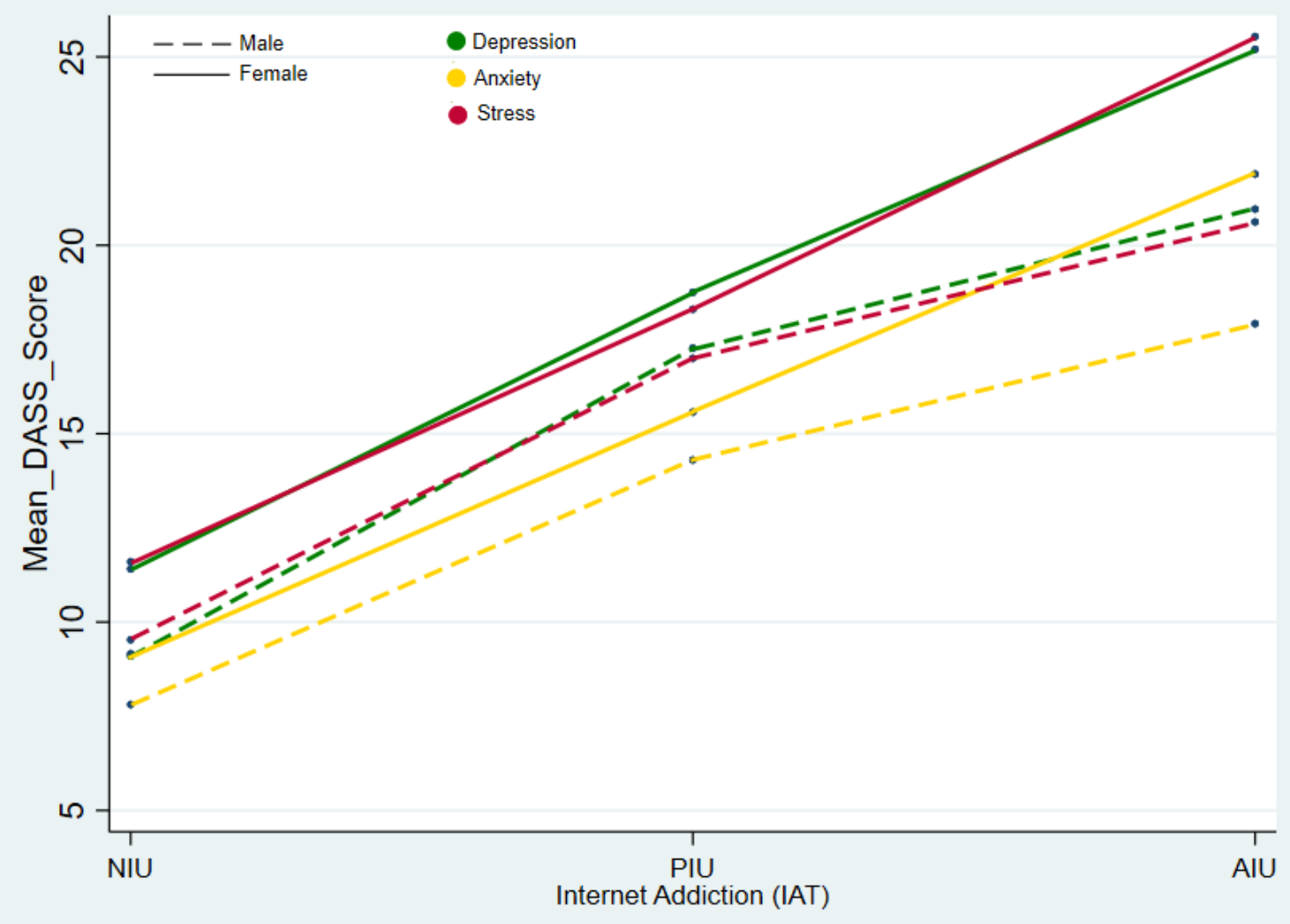

Figure 1

showing mean DASS scores of participants as a function of gender.

\section{Supplementary Files}

This is a list of supplementary files associated with this preprint. Click to download.

- IAanalysistables.docx 